\title{
Backbone assignment of $E$. coli NfsB and the effects of addition of the cofactor analogue nicotinic acid
}

\author{
Eva I. Hyde ${ }^{1} \mathbb{D} \cdot$ Alex Ka-Wing Chau $^{1,3} \cdot$ Lorna J. Smith $^{2}$ (D)
}

Received: 26 September 2020 / Accepted: 11 December 2020 / Published online: 9 January 2021

(c) The Author(s) 2021

\begin{abstract}
E. coli nitroreductase $\mathrm{NfsB}$ (also called $\mathrm{NfnB}$ ) has been studied extensively, largely due to its potential for cancer gene therapy. A homodimeric flavoprotein of 216 residues, it catalyses the reduction of nitroaromatics to cytotoxic hydroxylamines by $\mathrm{NADH}$ and NADPH and also the reduction of quinones to hydroxyquinones. Its role in vivo is not known but it is postulated to be involved in reducing oxidative stress. The crystal structures of the wild type protein and several homologues have been determined in the absence and presence of ligands, including nicotinate as a mimic of the headpiece of the nicotinamide cofactors. There is little effect on the overall structure of the protein on binding ligands, but, from the B factors, there appears to be a decrease in mobility of 2 helices near the active site. As a first step towards examining the dynamics of the protein in solution with and without ligand, we have assigned the backbone ${ }^{13} \mathrm{C},{ }^{15} \mathrm{~N}$, and ${ }^{1} \mathrm{H}_{\mathrm{N}}$ resonances of $\mathrm{NfsB}$ and examined the effect of the binding of nicotinate on the amide ${ }^{15} \mathrm{~N}$, and ${ }^{1} \mathrm{H}_{\mathrm{N}}$ shifts.
\end{abstract}

Keywords Nitroreductase $\cdot$ Flavoprotein $\cdot$ Nicotinic acid $\cdot$ Titration

\section{Biological context}

E. coli nitroreductase $\mathrm{NfsB}$ is a member of a large superfamily of nitroreductases of over 24,000 sequences, with diverse enzymatic activities, that are being studied for rational enzyme design (Akiva et al. 2017). The E. coli enzyme (also called $\mathrm{NfnB}$ ) was initially discovered as it causes bacteria to be sensitive to nitrofuran antibiotics, such as nitrofurantoin and nitrofurazone (McCalla et al. 1978). Nitrofurantoin is still recommended for use against urinary infections, while nitrofurazone was used topically in skin wounds. Little resistance to these antibiotics has developed, despite several decades of use. The sensitivity of bacteria to these nitroaromatics is because nitroreductases catalyse their reduction to

Eva I. Hyde

E.I.Hyde@bham.ac.uk

Lorna J. Smith

lorna.smith@chem.ox.ac.uk

1 School of Biosciences, University of Birmingham, Edgbaston, Birmingham B15 2TT, UK

2 Department of Chemistry, University of Oxford, Oxford OX1 3QR, UK

3 Present Address: Legislative Council Complex, Central, Hong Kong highly cytotoxic hydroxylamines, by NADH and NADPH. This reaction is the basis for the potential use of NfsB in cancer gene therapy. Introduction of the $n f s B$ gene into cancer cells, for instance by use of a viral vector, followed by treatment with prodrugs such as CB1954 (5-aziridin-1-yl, 2, 4, dinitrobenzamide) has been shown to kill the cells and neighbouring cells (Searle et al. 2004). Similarly, delivery of $n f_{s} B$ followed by treatment with metronidazole has been used for selective cell ablation in the study of animal development (Curado et al. 2007). The NfsB homologue from Enterobacter cloacae, in turn, has been studied for use in bioremediation of TNT and in chemical transformations (Miller et al. 2018). In addition to reduction of nitroaromatics, NfsB reduces quinones to quinols, in a 2-electron step, without producing radicals. It has been postulated therefore to be involved in reducing oxidative stress. In support of a role in this, its expression is upregulated by the transcription activator MarA (Barbosa and Levy 2002).

The $n f s B$ gene encodes 217 amino acids, but, like many $E$. coli proteins, the first methionine, residue is cleaved in vivo so the protein contains 216 amino acids per subunit. It is a homodimer with a tightly bound FMN cofactor in each subunit. The crystal structures of the wild type NfsB protein (Lovering et al. 2001; Parkinson et al. 2000), mutants, and several homologues have been determined 
(Fig. 1). Each subunit contains 11 helices and 5 highly twisted $\beta$-strands with an extensive subunit interface. The FMN cofactors lie on opposite sides of the long, $G$ helices, that cross each other, and each cofactor contacts both subunits. There is little effect on the overall structure of the protein on binding ligands, but, from the B factors, there seems to be a decrease in mobility at the end of helix E and throughout helix F, residues 105-132 (Lovering et al. 2001; Parkinson et al. 2000). These two helices protrude from the core of the protein but are near the active site. Protein flexibility has been postulated to be important for the catalytic activity of many enzymes, including the homologous NADH oxidase (NOX) from Thermus thermophilus. The NMR relaxation properties of NOX, have been determined (Miletti et al. 2011) and molecular dynamics simulations have compared the dynamics of NOX, a thermophilic enzyme, to those of the mesophilic NfsB as a function of temperature, suggesting again that helices $\mathrm{E}$ and $\mathrm{F}$ may influence stability and activity (Merkley et al. 2010). There have been other molecular dynamics calculations of $E$. coli $\mathrm{NfsB}$ (Christofferson et al. 2012) and the homologous Enterobacter cloacae enzyme (Christofferson 2020), to try to resolve the molecular mechanism of nitroaromatic reduction. As a first step towards examining the dynamics of the protein in solution with and without ligand, we have assigned the backbone ${ }^{13} \mathrm{C},{ }^{15} \mathrm{~N}$, and ${ }^{1} \mathrm{H}_{\mathrm{N}}$ resonances of $\mathrm{NfsB}$ and examined the effect of the binding of sodium nicotinate,

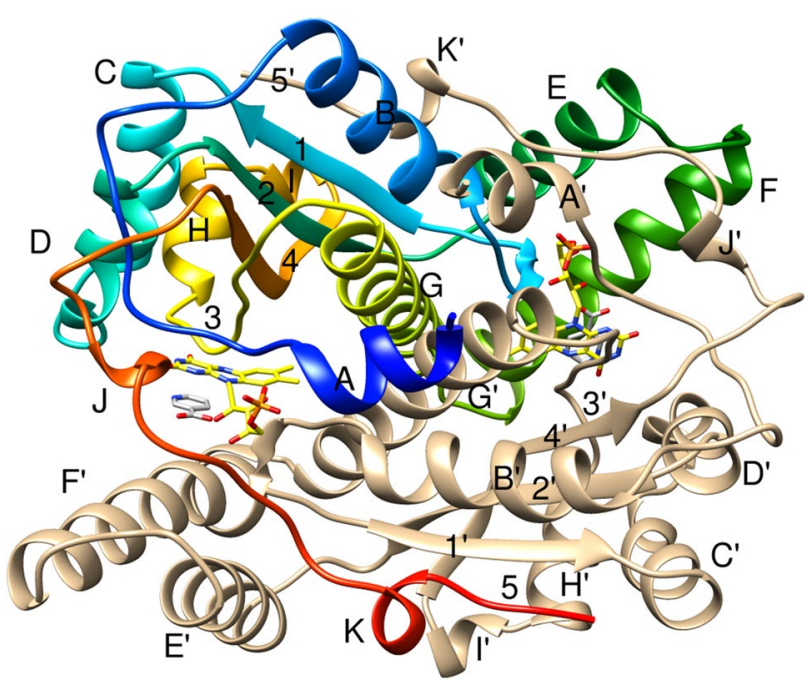

Fig. 1 Crystal structure of E. coli NfsB bound to nicotinate. Ribbon diagram of the 3D structure of E. coli $\mathrm{NfsB}$ bound to nicotinate (from 1ICR (Lovering et al. 2001)). One subunit is coloured in rainbow colours, blue to red, from the $\mathrm{N}$-terminus to the $\mathrm{C}$-terminus, with the helices labelled A-K and the strands numbered $1-5$. The other subunit is in beige and labelled $\mathrm{A}^{\prime}-\mathrm{K}^{\prime}$ and $1^{\prime}-5^{\prime}$. The FMN cofactor and nicotinate are shown as sticks, with FMN carbon backbone in yellow, the nicotinate in grey and other atoms in CPK colours as a mimic of the $\mathrm{NAD}(\mathrm{P}) \mathrm{H}$ headpiece, on the amide ${ }^{15} \mathrm{~N}$ and ${ }^{1} \mathrm{H}_{\mathrm{N}}$ shifts.

\section{Methods and experiments}

\section{Protein expression and purification}

Although NfsB expressed well in minimal M9 medium from the trp-promoter in plasmid pPM24 in E. coli DH5 $\alpha$ (Michael et al. 1994), no expression was found when the strain was grown in $\mathrm{D}_{2} \mathrm{O}$ in this medium. The $n f s B$ gene was amplified from $E$. coli DH5 $\alpha$ and cloned into pET11c, expressed without tags from E. coli BL21 in M9 medium, and purified as described previously (Lovering et al. 2001). Prior to the NMR experiments it was dialysed into $20 \mathrm{mM}$ sodium phosphate buffer, pH 7.0, 0.05 mM EDTA. For assignment, the sample was ${ }^{13} \mathrm{C} /{ }^{15} \mathrm{~N} /{ }^{2} \mathrm{D}$ labelled by growth of the $E$. coli in M9 medium containing $1 \mathrm{~g} /{ }^{15} \mathrm{~N}-\mathrm{NH}_{4} \mathrm{Cl}$, and $2 \mathrm{~g} / 1{ }^{13} \mathrm{C}_{6}$-glucose as the only nitrogen and carbon sources and $80 \% \mathrm{D}_{2} \mathrm{O}$. For the titration experiments with nicotinic acid, the protein was labelled with ${ }^{15} \mathrm{~N}$ only. The expressed protein contained FMN but, to maintain full saturation with the cofactor, $20 \mu \mathrm{M}$ FMN was added to all buffers throughout protein purification, apart from the final dialysis. That the protein was fully bound with FMN was verified by measuring the ratio of absorbance of the protein preparation at $373 \mathrm{~nm}$ and $454 \mathrm{~nm}$ (where only the FMN absorbs) and at $280 \mathrm{~nm}$ (where both FMN and protein absorb).

\section{NMR spectroscopy}

For assignment of the spectrum of the protein in the absence of ligand, HNCOCACB and HNCACB spectra were recorded on a Varian $800 \mathrm{MHz}$ spectrometer at $37^{\circ} \mathrm{C}$. HNCOCA, HNCA, HNCO and HNCACO spectra were taken on a Varian $600 \mathrm{MHz}$ spectrometer at $30^{\circ} \mathrm{C}$ or $37{ }^{\circ} \mathrm{C}$, all with the triply labelled protein and deuterium decoupling. Assignments were confirmed where possible, by looking for sequential NH-NH NOEs in a ${ }^{15} \mathrm{~N}-{ }^{1} \mathrm{H}$ NOESY-HSQC taken at $600 \mathrm{MHz}$ using a ${ }^{15} \mathrm{~N}$-labelled sample.

Spectra were processed with NMRPipe (Delaglio et al. 1995) and analysed with CCPN software (Vranken et al. 2005), or with NMRView5 (Johnson and Blevins 1994) and UCSF SPARKY (Goddard and Kneller 2008).

In the titrations, small aliquots from a stock solution of $89 \mathrm{mM}$ sodium nicotinate in the same buffer as the protein, were added to $(0.4 \mathrm{ml})$ of $0.53 \mathrm{mM}$ protein. $1 \mathrm{D}{ }^{1} \mathrm{H}$ NMR spectra and $2 \mathrm{D}{ }^{15} \mathrm{~N}-{ }^{1} \mathrm{H}$ HSQC spectra were taken after each addition, using a Varian $600 \mathrm{MHz}$ spectrometer at 
$30{ }^{\circ} \mathrm{C}$ and, in a separate titration, at $35^{\circ} \mathrm{C}$. The concentration of ligand ranged from 0 to $8.9 \mathrm{mM} .{ }^{15} \mathrm{~N}-{ }^{1} \mathrm{H}$ NOESYHSQC spectra, with a mixing time of $0.1 \mathrm{~s}$, were taken before and after the titration. The spectra were assigned by following the shift changes over the titration at both temperatures and assignments confirmed, where possible, by comparing the ${ }^{1} \mathrm{H}-{ }^{15} \mathrm{~N}-\mathrm{HSQC}$ NOESY spectra of the protein with and without ligand. The changes in ${ }^{15} \mathrm{~N}$ shifts between the free protein and protein in the presence of 10 equivalents of ligand were weighted by a factor of 0.15 relative to the ${ }^{1} \mathrm{H}_{\mathrm{N}}$ shifts as in Mulder et. al (Mulder et al. 1999).

The shifts of each nicotinate proton (y) as a function of ligand concentration $(\mathrm{x}$ ) were fitted to a simple hyperbola to estimate the bound shift (y0)

$y=y 0+\frac{a * x}{K d+x}$

where $\mathrm{a}$ is the difference between the bound and the free shift and $\mathrm{K}_{\mathrm{d}}$ is the apparent dissociation constant.

\section{Extent of assignments and data deposition}

\section{Free protein}

The expressed protein is a dimer with 216 residues per monomer, of which 9 are proline. The high molecular mass $(48 \mathrm{kDa})$ meant that the protein needed to be deuterated for good signal in triple resonance experiments and the spectra were taken at relatively high temperature to reduce the rotational correlation time. Figure 2 shows the ${ }^{1} \mathrm{H}_{-}{ }^{15} \mathrm{~N}$ HSQC spectrum of the protein with the assignments. 200 $\mathrm{NH}$ residues were assigned in the triple resonance spectra. $\mathrm{NH}$ peaks for the first residue Asp 2 (not expected), and for His 11, Thr 41, Asn 67, Asp 92, Ala 109, and Val 196 were not observed, while some other peaks had very low intensity in the spectra (Fig. 3a). $C \alpha, C \beta$ and $C^{\prime}$ peaks were assigned for all residues. These assignments have been deposited in the BioMagResBank, with ID 50476.

In addition to the backbone resonances, $\mathrm{NH}$ peaks were assigned to the indole $\mathrm{NH}$ groups of the three tryptophan residues but were not assigned further. These are at 11.80, 135.0; 9.93, 129.8; and 10.96, $130.7 \mathrm{ppm},{ }^{1} \mathrm{H}$ and ${ }^{15} \mathrm{~N}$ shift, respectively.

His $195 \mathrm{NH}$, which is hydrogen-bonded to Asp 160, and Ser $185 \mathrm{NH}$, which is hydrogen-bonded to Asp 163 and close to Phe 167 , have ${ }^{1} \mathrm{H}$ shifts greater than $10 \mathrm{ppm}$, and
Ser 185 also has a high ${ }^{15} \mathrm{~N}$ shift. Ala $78 \mathrm{NH}$ is close to Phe 16 which may cause its ${ }^{1} \mathrm{H}$ shift close to $6 \mathrm{ppm}$. Met $75 \mathrm{NH}$ has an unusually low ${ }^{15} \mathrm{~N}$ shift. It is close to the backbone carbonyl oxygen of both Glu 72 and Arg 73.

The secondary structure of the protein was determined based on the chemical shifts, using DANGLE (Cheung et al. 2010) and agrees well with the crystal structure (1ICR (Lovering et al. 2001)), Fig. 3b. The NH order parameters for the protein were also calculated from the chemical shifts, using the RCI method (Berjanskii and Wishart 2008) in TALOS-N (Shen and Bax 2013), Fig. 3c. Most of the order parameters are above 0.8 , apart from a few residues in loops, suggesting that the protein is structurally quite rigid, as found for NOX (Miletti et al. 2011). The calculated order parameters do not suggest greater flexibility of helices $\mathrm{E}$ and $\mathrm{F}$ as shown by the B factors of the free protein (Parkinson et al. 2000) and by the molecular dynamics simulations (Merkley et al. 2010). Instead the low order parameters, Fig. 3b, seem to correlate with low NH peak intensities, Fig. 3a. This suggests that the weaker intensities for loop $\mathrm{NH}$ resonances are due to enhanced fast motion, and thus more $\mathrm{NH}$ exchange.

\section{Nicotinic acid binding}

The shifts of the aromatic protons of the ligand were followed in $1 \mathrm{D}{ }^{1} \mathrm{H}$ NMR spectra taken on titration of nicotinate into ${ }^{15} \mathrm{~N}$-labelled NfsB (Fig. 4a, Table 1), while the shifts of the amide groups were followed using ${ }^{15} \mathrm{~N}-{ }^{1} \mathrm{H}$ HSQC experiments. (Fig. 4b).

Three of the proton resonances of the ligand were in fast exchange, while one (H5, a triplet) was severely linebroadened on binding and so only observed at relatively high concentrations of ligand. The nicotinate protons shift to lower frequency on binding, apart from the $\mathrm{H} 2$ which shows a slight shift to higher frequency. The nicotinic acid binds parallel to the FMN ring system, and the protons would be expected to be greatly affected by this, as well as by protein contacts.

For the protein, a few NH peaks were not observed and several peaks overlapped either in spectra taken in the absence of ligand, or taken in its presence. Where possible, the assignments of the ligand-bound protein were confirmed by comparing the ${ }^{1} \mathrm{H}-{ }^{15} \mathrm{~N}-\mathrm{HSQC}$ NOESY spectra of the protein with and without ligand. These assignments have been deposited in the BMRB under ID 50576.

Several amide resonances shifted on titration with nicotinate and some changed intensity. Assignments of $\mathrm{NH}$ peaks from residues Ser 40, Phe 70, Glu 72, Phe 123, Phe 124, Asp 
A

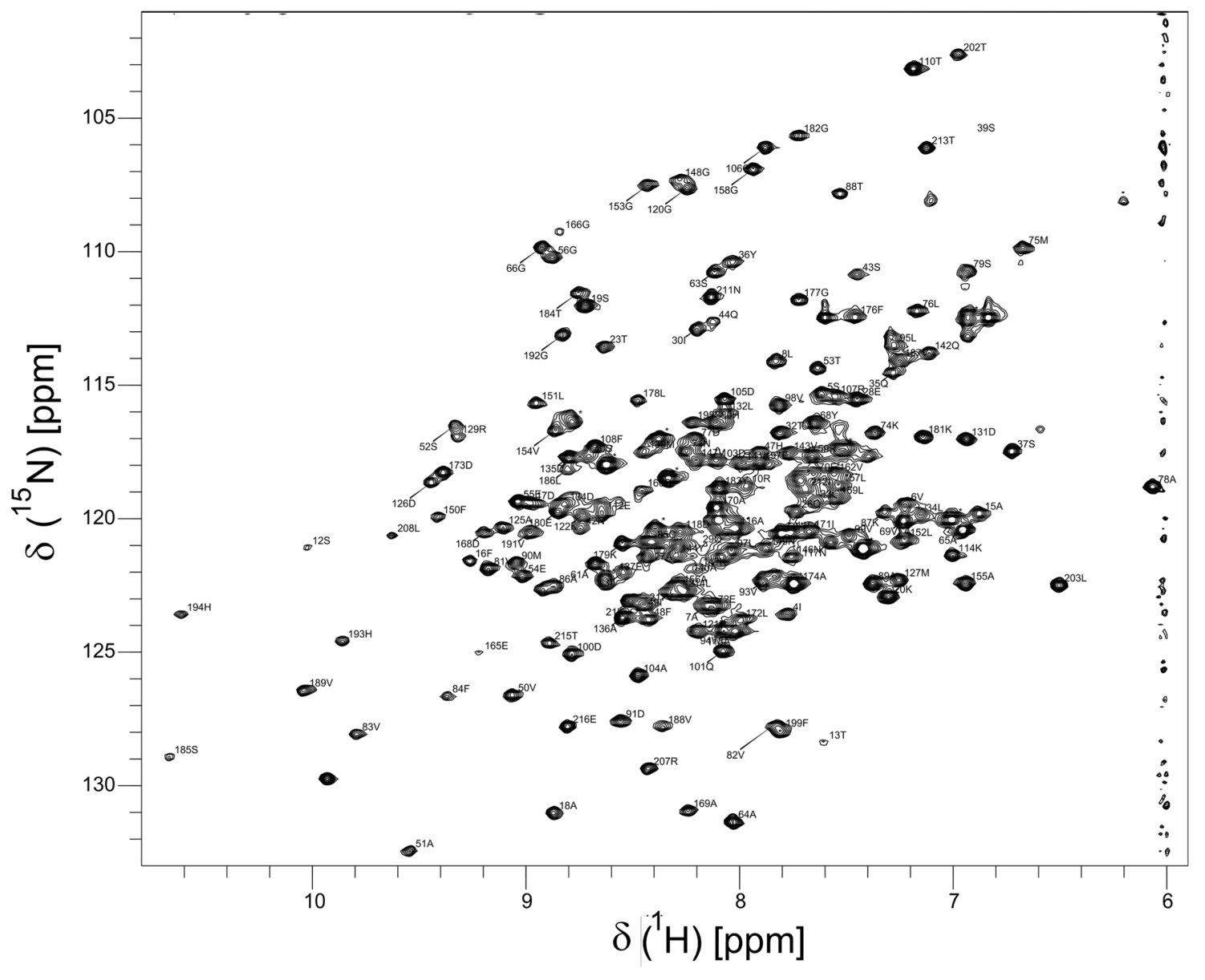

B

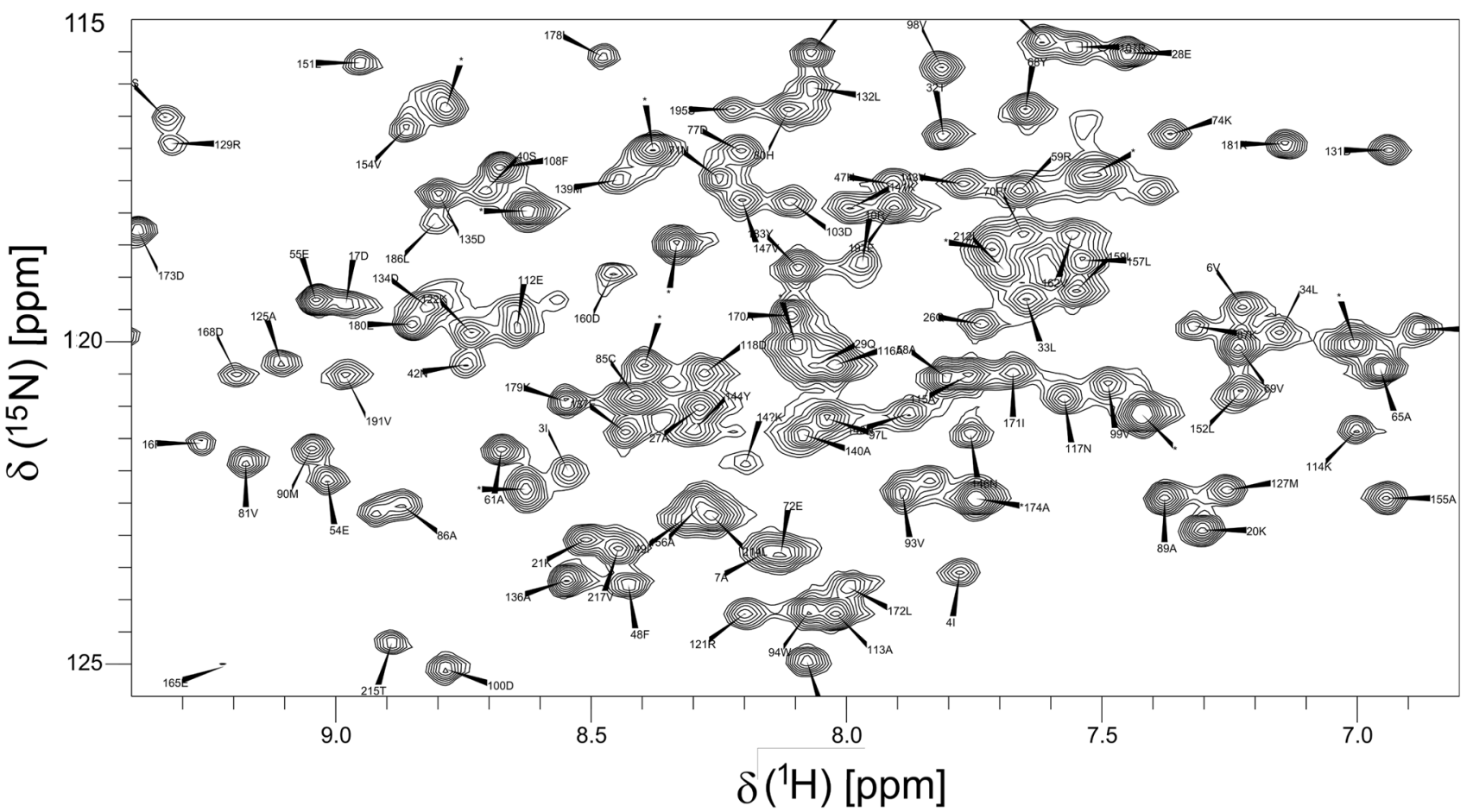

Fig. $2{ }^{1} \mathrm{H}^{-15} \mathrm{~N}$ HSQC NMR spectrum of $E$. coli $\mathrm{NfsB}$, taken at $600 \mathrm{MHz}$ and $35{ }^{\circ} \mathrm{C}$, in $20 \mathrm{mM}$ sodium phosphate buffer, $\mathrm{pH}$ 7.0, $0.05 \mathrm{mM}$ EDTA. a- full spectrum of the amide region, with $\mathrm{NH}$ assignments labelled, side chains are not assigned. Asterisks indicate overlapping peaks. b- inset of central region of the spectrum, with $\mathrm{NH}$ assignments 
135 and Val 162 remain tentative, because of peak overlap. The largest overall shift changes were seen at residues 165 and 166, and between residues 120-129. Smaller, but significant, shift changes were observed at Asn 42, Ser 43, Trp 138, Val 188 and Asn 200 (Fig. 4b). The amino acids whose $\mathrm{NH}$ shifts were most affected by titration are shown in the crystal structure of the protein complex in Fig. 5. Changes in peak intensity, both increases and decreases, were observed for many resonances across the whole protein, often for amino acids in loops.

Nicotinic acid makes direct contact with Ser 40, Thr 41, Phe 124, Glu165, Gly 166, Leu 203 and the FMN cofactor. Thr 41 was not identified in the spectrum, but Ser 40 and residues 42 and 43 show significant shift changes and decrease in intensity on addition of nicotinate. Residues 120-129 are in helix F, and the largest ${ }^{15} \mathrm{~N}$ shift changes in the protein are at residues 122, 124 and 125, at or near Phe 124 , the residue directly contacting the nicotinate. Glu 165 and Gly 166 also form direct contacts with the ligand and show the largest weighted shift changes overall and large decreases in peak intensity. Leu 203 and Thr 202 show significant ${ }^{15} \mathrm{~N}$ shifts, but little shift in ${ }^{1} \mathrm{H}$ and hence a small weighted overall shift, however Asn 200, which contacts Thr 202, among other residues, shows a larger ${ }^{1} \mathrm{H}$ shift, giving a larger weighted overall shift on binding ligand, despite having a small change in ${ }^{15} \mathrm{~N}$ shift. The other significant shifts are of $\operatorname{Trp} 138$, which is in the active site and contacts Glu 165 via the indole $\mathrm{NH}$, and Val 188, which contacts Ile 164.

While the largest weighted overall shift changes in helix $\mathrm{F}$ are at residues 126 and 127, most of the residues of this helix, those from 116 to 129 , show significant shifts in ${ }^{1} \mathrm{H}$ or ${ }^{15} \mathrm{~N}$. This suggests that this helix is affected by more than just direct interaction with the ligand, possibly a change in mobility as there is no change in the crystal structure of the protein with ligand. These residues are in the region with higher B factors in the crystal structure of the free protein.

Other residues that show a significant shift only in ${ }^{15} \mathrm{~N}$ on ligand binding include Tyr 68 and Asn 71 which are both close to Gly 166, while Ala 65 and Phe 70, which also shift, are close to Tyr 68 . Tyr 68 is close to Phe 124 on the opposite subunit, the residue that contacts the ligand directly. The side chains of Phe 124 and Tyr 68 are likely to control the entry of the ligands into the active site of the protein (Fig. 5). A wide range of mutations at both of these amino acids, as well as at Phe 70, enhance the activity of the protein for the bulky prodrug CB1954 (Grove et al. 2003; Race et al. 2007). The residues Glu 165, Trp 138 and Ser 40 have recently been proposed to be important in catalysis in Enterobacter cloacae nitroreductase, in stabilising a bound water molecule in the correct orientation for donation of a proton in the reduction mechanism, while His 128 binds the nitro group to be reduced (Christofferson 2020). The shift changes observed further from the direct site of binding may therefore reflect motions affecting ligand binding and ultimately catalysis. 
A

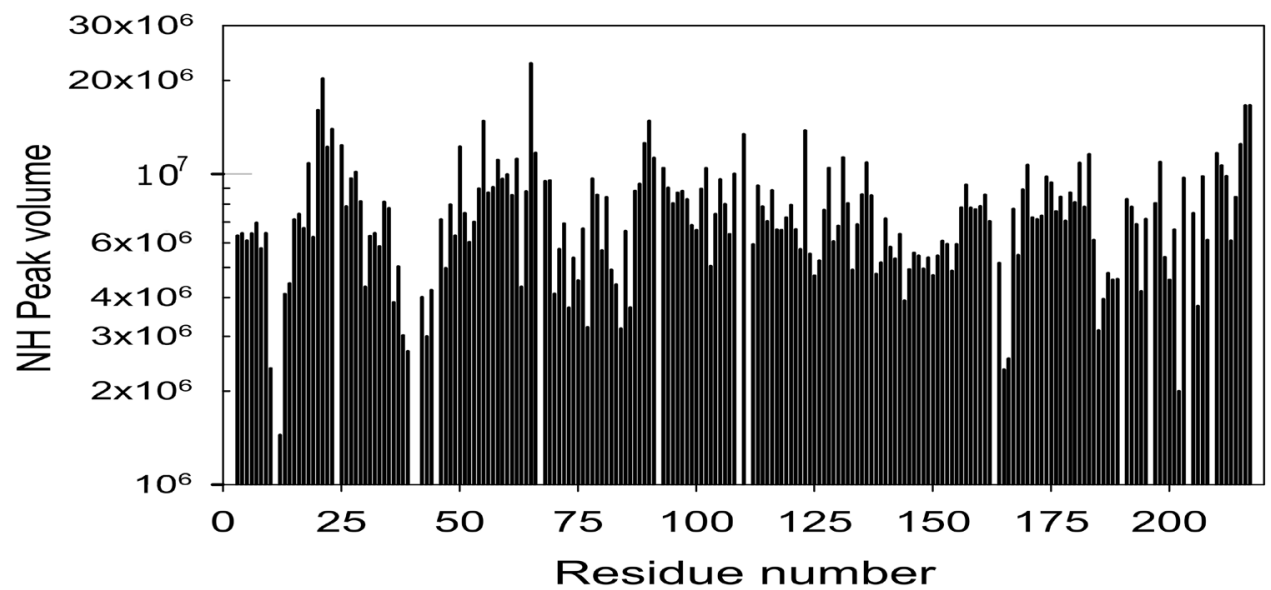

B
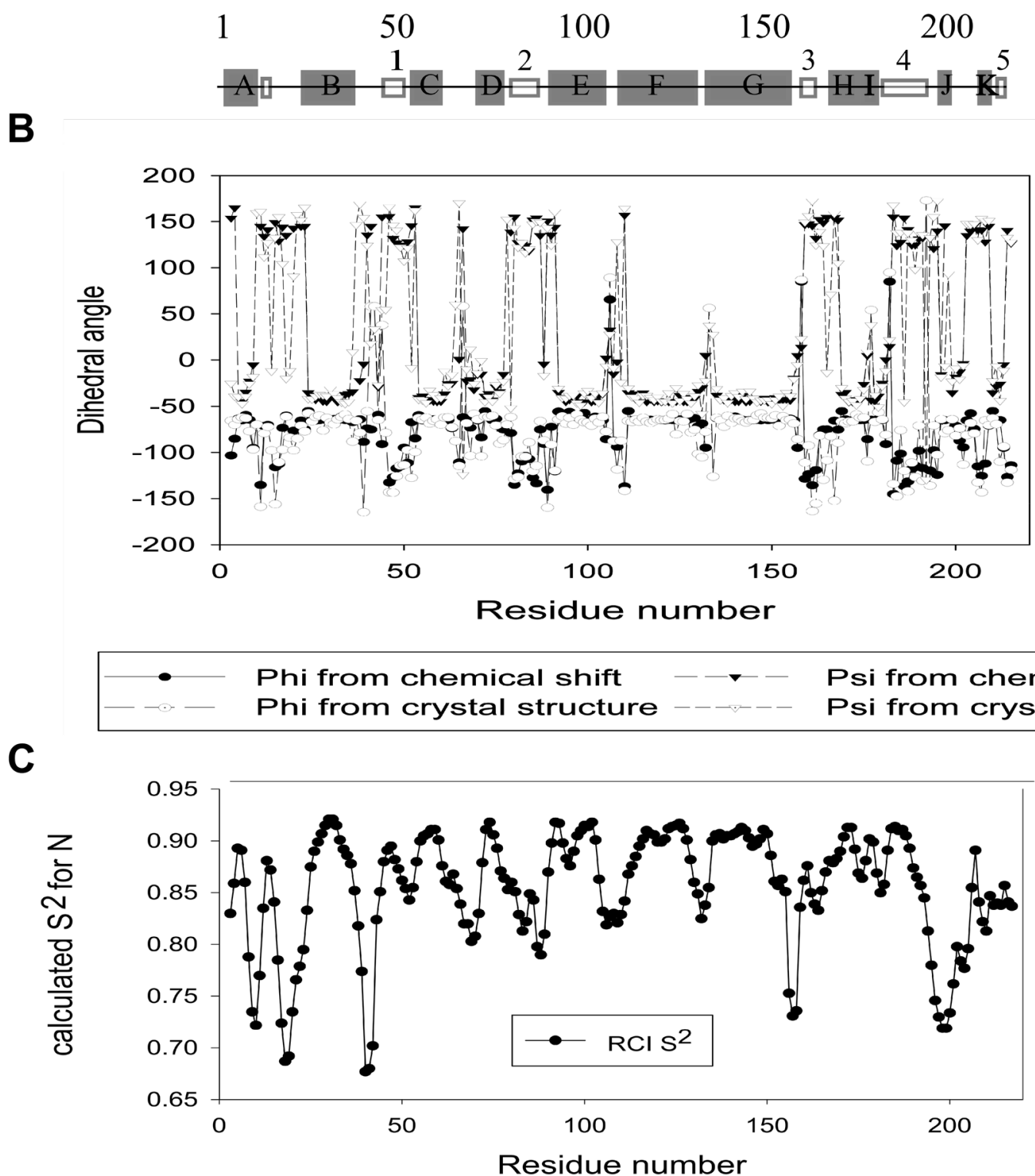
4Fig. 3 NH Peak volumes, secondary structure and $\mathrm{S}^{2}$ values of $E$. coli $\mathrm{NfsB}$, based on the chemical shifts. a Relative peak volumes from a 3D HNCO spectrum of $E$. coli $\mathrm{NfsB}$, taken at $600 \mathrm{MHz}$ and $35^{\circ} \mathrm{C}$, in $20 \mathrm{mM}$ sodium phosphate buffer, $\mathrm{pH} 7.0,0.05 \mathrm{mM}$ EDTA. CentreSecondary structure from the X-ray crystal structure of the protein, from 1ICR (Lovering et al. 2001)- helices shown in grey boxes labelled with letters, strands shown in white boxes with numbers. b Comparison of secondary structure of the free $E$. coli $\mathrm{NfsB}$ determined from the chemical shifts by the program DANGLE (Cheung et al. 2010) and that determined by X-ray crystallography from 1ICR (Lovering et al. 2001). Circles, phi angle, triangles psi angle, grey symbols values from DANGLE, white symbols values from 1ICR. $\mathrm{C} \mathrm{S}^{2}$ values for the NH groups based on the chemical shifts, calculated using the RCI method (Berjanskii and Wishart 2008) in TALOS-N (Shen and Bax 2013)
Table 1 Estimated bound shifts, and apparent dissociation constants for Nicotinate, using fit of shifts to the equation for a simple hyperbola

\begin{tabular}{llll}
\hline Proton & Estimated bound shift & $\begin{array}{l}\text { Estimated change } \\
\text { in shift on binding }\end{array}$ & Apparent $\mathrm{K}_{\mathrm{d}}$ \\
\hline & $(\mathrm{ppm})$ & $(\mathrm{ppm})$ & $(\mathrm{mM})$ \\
$\mathrm{H} 2$ & $8.87 \pm 0.05$ & $0.050 \pm 0.003$ & $3.0 \pm 0.8$ \\
$\mathrm{H} 6$ & $7.84 \pm 0.04$ & $0.83 \pm 0.02$ & $2.2 \pm 0.4$ \\
$\mathrm{H} 4$ & $7.92 \pm 0.02$ & $0.35 \pm 0.01$ & $1.9 \pm 0.3$ \\
$\mathrm{H} 5$ & $7.2 \pm 0.2$ & $0.3 \pm 0.1$ & $2.5 \pm 4$ \\
\hline
\end{tabular}

\section{B Scaled shift differences}

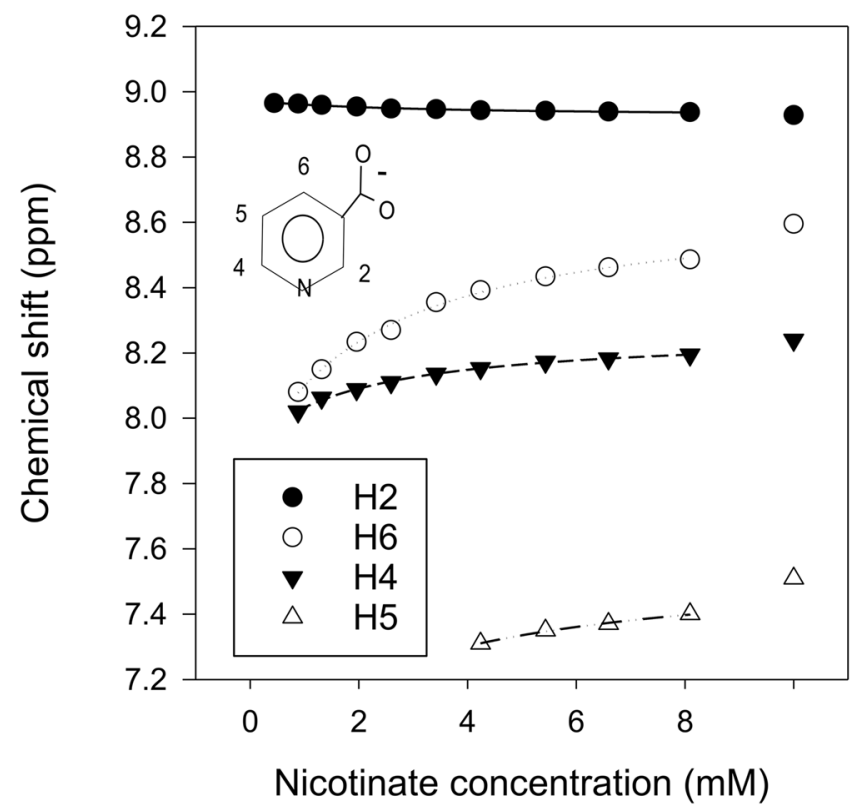

Fig. 4 Shifts on binding nicotinate. a Chemical shifts of nicotinate on titration into $E$. coli $\mathrm{NfsB}$. The initial protein concentration was $0.53 \mathrm{mM}$. Aliquots from a stock solution of $89 \mathrm{mM}$ sodium nicotinate in the same buffer as the protein, were added to $0.4 \mathrm{ml}$ protein solution. Shifts were followed by $1 \mathrm{D}{ }^{1} \mathrm{H}$ NMR spectra after each addition, using a Varian $600 \mathrm{MHz}$ spectrometer at $30^{\circ} \mathrm{C}$. The final symbols are those of the free ligand in the same buffer. Black circles- H2, white

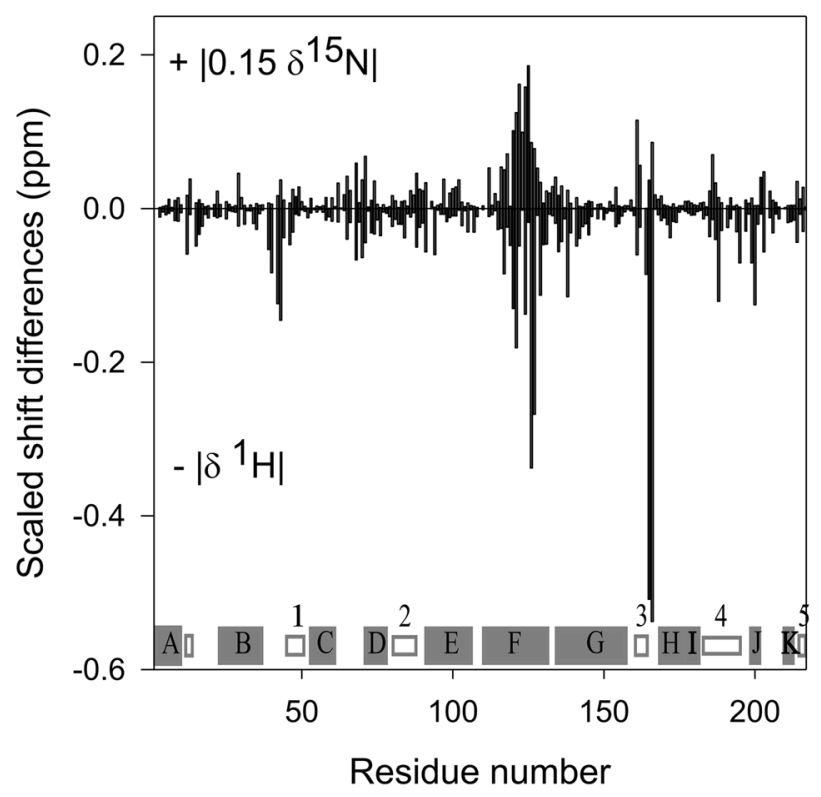

circles H6, black inverted triangle H4, white triangle H5. Lines show the fit of the data to hyperbolas (Eq. 1). b Changes in $\mathrm{NH}$ chemical shifts between free protein and protein containing 10 equivalents of nicotinate. Positive values, absolute value of 0.15 times the difference in ${ }^{15} \mathrm{~N}$ shift. Negative values: absolute values of changes in the ${ }^{1} \mathrm{H}$ shift. Below: secondary structure from 1ICR- helices shown in grey boxes labelled with letter, strands shown in white boxes with numbers 


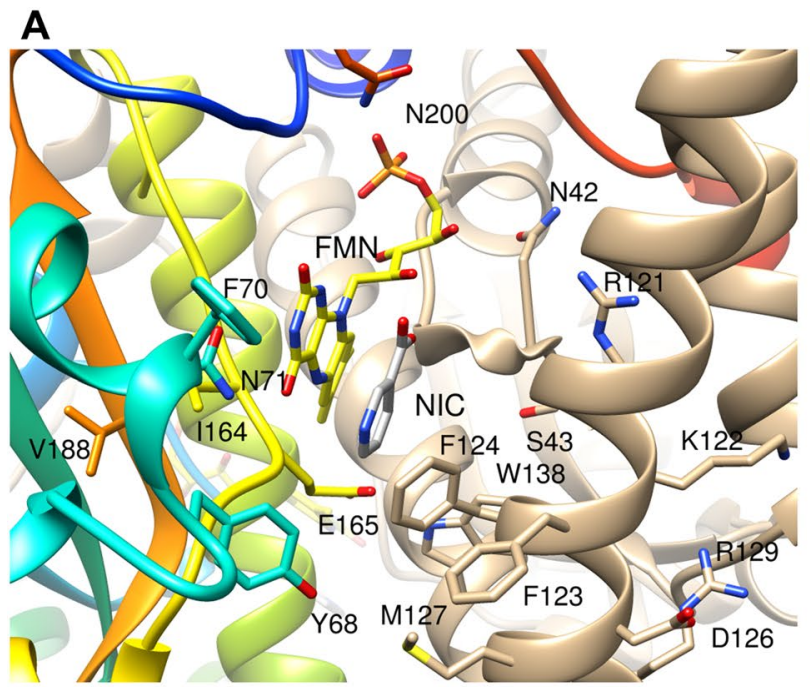

Fig. 5 Two views of the structure of $E$. coli NfsB near bound nicotinate, showing the residues with significant changes in chemical shifts on nicotinate binding. Ribbon diagram with the two subunits of the dimer in coloured as in Fig. 1 and the residues affected by nicoti-

\section{Conclusion}

We present nearly complete backbone assignments of $E$. coli $\mathrm{NfsB}$, a $48 \mathrm{kDa}$ homodimeric flavoprotein. The secondary structure from the chemical shifts are in good agreement with the crystal structure of the free protein, and the $\mathrm{NH}$ resonances most affected by nicotinate binding are at the binding site of the ligand. Additional chemical shift changes on ligand binding are seen further from the immediate binding site which may reflect other motions. These studies lay the foundations for studies of the dynamics of the protein or of other ligands binding to the protein in solution.

Acknowledgements We thank Tom Frenkiel and Geoff Kelly, at the MRC Biomedical NMR centre at NIMR, London, for their assistance in collecting the triple resonance spectra at $800 \mathrm{MHz}$. We thank Gill Anlezark, (Centre for Applied Microbiology and Research, Porton Down, Salisbury UK) for the initial clone and samples of NfsB; Peter Searle (Department of Cancer Studies, University of Birmingham, UK) for cloning the $n f s B$ gene into pET11c, Rosemary Parslow (School of Biosciences, University of Birmingham, UK) for skillful preparation of the protein and Jennifer Mitchell (Department of Chemistry, University of Oxford) for initial analysis of the NMR spectra while a student.

Author contributions EIH collected and transformed the NMR data. All authors contributed to the NMR assignments. EIH and LJS wrote the paper.

Funding This work was supported in part by the Medical Research Council, Grant Number G9815089. Spectra were collected at the NMR centre in Birmingham, funded by the Wellcome Trust and at the MRC Biomedical NMR centre at NIMR, London.

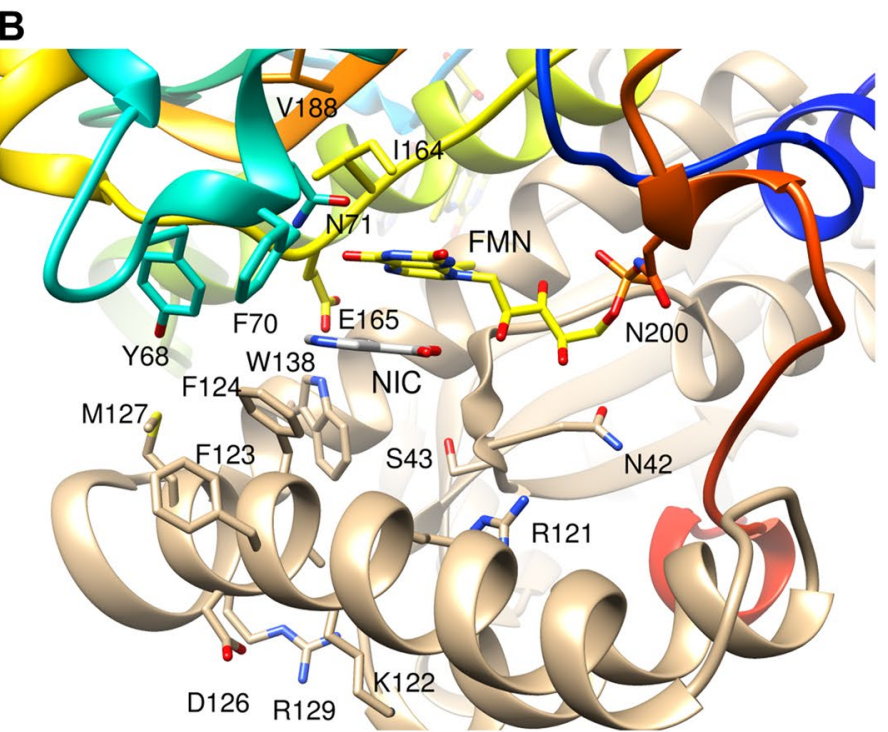

nate binding in stick form, labelled by residue. The FMN cofactor is in yellow and CPK colours and labelled, and the nicotinate is in light grey and CPK colours and labelled NIC

Data availability The backbone assignments of the free protein have been deposited in the BioMagResBank, ID 50476. The assignments of the amide resonances of the protein bound to nicotinate have been deposited under ID 50576.

\section{Compliance with ethical standards}

Conflict of interest All authors declare that they have no conflict of interest.

Open Access This article is licensed under a Creative Commons Attribution 4.0 International License, which permits use, sharing, adaptation, distribution and reproduction in any medium or format, as long as you give appropriate credit to the original author(s) and the source, provide a link to the Creative Commons licence, and indicate if changes were made. The images or other third party material in this article are included in the article's Creative Commons licence, unless indicated otherwise in a credit line to the material. If material is not included in the article's Creative Commons licence and your intended use is not permitted by statutory regulation or exceeds the permitted use, you will need to obtain permission directly from the copyright holder. To view a copy of this licence, visit http://creativecommons.org/licenses/by/4.0/.

\section{References}

Akiva E, Copp JN, Tokuriki N, Babbitt PC (2017) Evolutionary and molecular foundations of multiple contemporary functions of the nitroreductase superfamily. Proc Natl Acad Sci 114:E9549_ E9558. https://doi.org/10.1073/pnas.1706849114

Barbosa TM, Levy SB (2002) Activation of the Escherichia coli nfnB gene by MarA 45:191-202. https://doi.org/10.104 6/j.1365-2958.2002.03006.x

Berjanskii MV, Wishart DS (2008) Application of the random coil index to studying protein flexibility. J Biomol NMR 40:31-48. https://doi.org/10.1007/s10858-007-9208-0 
Cheung MS, Maguire ML, Stevens TJ, Broadhurst RW (2010) DANGLE: a Bayesian inferential method for predicting protein backbone dihedral angles and secondary structure. J Magn Reson 202:223-233. https://doi.org/10.1016/j.jmr.2009.11.008

Christofferson AJ (2020) Asymmetric ligand binding in homodimeric Enterobacter cloacae nitroreductase yields the Michaelis complex for nitroaromatic substrates. J Mol Model. https://doi. org/10.1007/s00894-020-4288-9

Christofferson A, Zhao LF, Pei Q (2012) Dynamic simulations as a complement to experimental studies of enzyme mechanisms. In: Christov C, Karabencheva-Christova T (eds) Structural and mechanistic enzymology: bringing together experiments and computing. Advances in protein chemistry and structural biology, vol 87. Elsevier, New York, pp 293-335. https://doi. org/10.1016/B978-0-12-398312-1.00010-X

Curado S, Anderson RM, Jungblut B, Mumm J, Schroeter E, Stainier DYR (2007) Conditional targeted cell ablation in zebrafish: a new tool for regeneration studies. Dev Dyn 236:1025-1035. https://doi.org/10.1002/dvdy.21100

Delaglio F, Grzesiek S, Vuister GW, Zhu G, Pfeifer J, Bax A (1995) NMRPipe: a multidimensional spectral processing system based on UNIX pipes. J Biomol NMR 6:277-293. https://doi. org/10.1007/BF00197809

Goddard TD, Kneller DG (2008) SPARKY 3. University of California, San Francisco

Grove JI et al (2003) Generation of Escherichia coli nitroreductase mutants conferring improved cell sensitization to the prodrug CB1954. Can Res 63:5532-5537

Johnson BA, Blevins RA (1994) NMR View-a computer-program for the visualization and analysis of NMR data. J Biomol NMR 4:603-614. https://doi.org/10.1007/Bf00404272

Lovering AL, Hyde EI, Searle PF, Scott AW (2001) The structure of Escherichia coli nitroreductase complexed with nicotinic acid: three crystal forms at $1.7 \AA, 1.8 \AA$ and $2.4 \AA$ resolution. J Mol Biol 309:203-213. https://doi.org/10.1006/jmbi.2001.4653

McCalla DR, Kaiser C, Green MHL (1978) Genetics of nitrofurazone resistance in Escherichia coli. J Bacteriol 133:10-16

Merkley ED, Parson WW, Daggett V (2010) Temperature dependence of the flexibility of thermophilic and mesophilic flavoenzymes of the nitroreductase fold. Protein Eng Des Sel 23:327-336. https:// doi.org/10.1093/protein/gzp090
Michael NP, Brehm JK, Anlezark GM, Minton NP (1994) Physical characterization of the Escherichia coli B gene encoding nitroreductase and its overexpression in Escherichia coli K12. FEMS Microbiol Lett 124:195-202. https://doi. org/10.1111/j.1574-6968.1994.tb07284

Miletti T, Farber PJ, Mittermaier A (2011) Active site dynamics in NADH oxidase from Thermus thermophilus studied by NMR spin relaxation. J Biomol NMR 51:71. https://doi.org/10.1007/s1085 8-011-9542-0

Miller A-F, Park JT, Ferguson KL, Pitsawong W, Bommarius AS (2018) Informing efforts to develop nitroreductase for amine production. Molecules. https://doi.org/10.3390/molecules23020211

Mulder FAA, Schipper D, Bott R, Boelens R (1999) Altered flexibility in the substrate-binding site of related native and engineered highalkaline Bacillus subtilisins 11 Edited by P. E Wright. J Mol Biol 292:111-123. https://doi.org/10.1006/jmbi.1999.3034

Parkinson GN, Skelly JV, Neidle S (2000) Crystal structure of FMNdependent nitroreductase from Escherichia coli B: a prodrugactivating enzyme. J Med Chem 43:3624-3631. https://doi. org/10.1021/jm000159m

Race PR, Lovering AL, White SA, Grove JI, Searle PF, Wrighton CW, Hyde EI (2007) Kinetic and structural characterisation of Escherichia coli nitroreductase mutants showing improved efficacy for the prodrug substrate CB1954. J Mol Biol 368:481-492. https://doi. org/10.1016/j.jmb.2007.02.012

Searle PF et al (2004) nitroreductase: a prodrug-activating enzyme for cancer gene therapy. Clin Exp Pharmacol Physiol 31:811-816. https://doi.org/10.1111/j.1440-1681.2004.04085.x

Shen Y, Bax A (2013) Protein backbone and sidechain torsion angles predicted from NMR chemical shifts using artificial neural networks. J Biomol NMR 56:227-241. https://doi.org/10.1007/s1085 8-013-9741-y

Vranken WF et al (2005) The CCPN data model for NMR spectroscopy: development of a software pipeline. Proteins 59:687-696. https://doi.org/10.1002/prot.20449

Publisher's Note Springer Nature remains neutral with regard to jurisdictional claims in published maps and institutional affiliations. 